\title{
Influence of Atmosphere and Basicity on Softening and Melting Behaviors of the $\mathrm{CaO}-\mathrm{FeO}-\mathrm{SiO}_{2}-\mathrm{Al}_{2} \mathrm{O}_{3}-\mathrm{MgO}$ System
}

\author{
Shigeru UEDA, ${ }^{1) *}$ Takahiro $\mathrm{MIKI}^{2)}$ Sun-Joong $\mathrm{KIM}^{3)}{ }^{3)} \mathrm{Xu} \mathrm{GAO}^{1)}$ Hiroshi NOGAMI ${ }^{1)}$ and Shin-ya KITAMURA ${ }^{1)}$ \\ 1) Institute of Multidisciplinary Research Advanced Material, Tohoku University, 1-1 Katahira 2 Aoba-ku Sendai, $980-8577$ Japan. \\ 2) School of Engineering, Tohoku University, 6-6 Aoba Aramaki Aoba-ku Sendai, 980-8579 Japan. \\ 3) Dept. of Materials Science and Engineering, Chosun University, 309, Pilmun-daero, Dong-gu, Gwangju, 61452 Korea.
}

(Received on March 8, 2019; accepted on December 9, 2019)

\begin{abstract}
In this study, we analyze the softening and melting behaviors of the $\mathrm{CaO}-\mathrm{FeO}-\mathrm{SiO}_{2}-\mathrm{Al}_{2} \mathrm{O}_{3}-\mathrm{MgO}$ system for improving gas permeability in a blast furnace. The temperature of the oxide is increased to 1723 or $1773 \mathrm{~K}$ in a $\mathrm{CO} / \mathrm{CO}_{2}$ mixture; the softening and melting temperatures and the temperature of penetration into the coke bed are measured. Because the $\mathrm{CO} / \mathrm{CO}_{2}$ ratio in the atmosphere influences the stable state of iron or iron oxide, the softening and melting behaviors are investigated for numerous $\mathrm{CO} / \mathrm{CO}_{2}$ ratios. We observe that the reduction of the sample progresses in an atmosphere with a high $\mathrm{CO} / \mathrm{CO}_{2}$ ratio, and thus, the softening temperature increases. Because the composition of the oxidation phase influences the solidus and liquidus temperatures, the influence of basicity on the phenomena is also investigated, and a method of reducing the difference between the softening and dripping temperatures is discussed.
\end{abstract}

KEY WORDS: blast furnace; coke bed; iron ore; softening; melting; gas permeability.

\section{Introduction}

In blast furnace operation, there is a move to produce iron using less carbonaceous material and coke in order to reduce the environmental load and decrease production costs. Coke acts as a reducing agent and a structural material that maintains the gas permeability of the packed bed in the furnace. Replacing the coke with a hydrogen-based gas or pulverized coal decreases the ratio of coke to iron ore and makes it difficult to maintain gas permeability. The volume of gas used is directly linked to the productivity of the blast furnace. In addition, gas permeability is directly related to the stability of the operation. The packed bed in the blast furnace is mainly composed of coke and ore layers, and it can be classified into a lumpy zone, a cohesive zone, and a dripping zone, depending on the state of the iron ore. In the cohesive zone particularly, since the iron ore partially melts and forms a half-melted integrated layer in the packed bed, ${ }^{1)}$ the pressure loss becomes large, which greatly affects the gas permeability in the blast furnace. ${ }^{2-9)}$ Solid-liquid phases coexist in the cohesive and dripping zones, and since the liquid fills the void of the packed bed, the pressure loss in these zones is larger than that of the lumpy zone.

Therefore, to promote low coke operations of a blast furnace, it is necessary to reduce pressure loss in the cohesive zone. In order to improve gas permeability of the cohesive zone, it is effective to reduce the thickness of the cohesive layer and activate the coke slit. ${ }^{10,11)}$ If the softening temperature of the cohesive layer is increased and the melting

\footnotetext{
* Corresponding author: E-mail: tie@tohoku.ac.jp

DOI: https://doi.org/10.2355/isijinternational.ISIJINT-2019-136
}

and dripping temperatures are decreased, the cohesive layer will be thinner. ${ }^{12)}$ In previous research, the relationship between the effects of $\mathrm{FeO}$ concentration, basicity, atmosphere and the liquid phase ratio on the variation in softening temperature of iron ore were reported. Temperature of softening is determined by both the initial composition and the mineral constituents, ${ }^{13,14)}$ but an increase in the liquid ratio is influenced by composition. Since iron oxide is reduced by the atmosphere in the blast furnace, the $\mathrm{FeO}$ concentration of the oxide in the iron ore changes, which affects the increase in the liquid phase ratio and the melting behavior. In addition, the dripping temperature of iron ore was not only determined by increasing the liquidus temperature and the liquid phase ratio, it was also affected by the wettability with coke. ${ }^{15-17)}$ The reduction reaction of the iron oxide affects the softening and wetting of the oxide melt. ${ }^{18)}$

The melting and dripping phenomena of molten slag and iron were also investigated. ${ }^{19,20)}$ In previous reports, ${ }^{21,22)}$ in a $\mathrm{FeO}$ stable atmosphere, the temperature at which the oxide became droplets increased with a reduction in the oxygen partial pressure, but the effect on the temperature of softening and penetration into the coke bed was small. Although the contact angle of the oxide system related to the iron ore and the carbon-based substrate have been extensively studied, ${ }^{23)}$ it is known that both the reaction at the interface and the contact time will change the wetting angle. ${ }^{24-26)}$ The relationship between wettability and delaying the liquid in the packed bed has also been studied, ${ }^{27-30)}$ however the wetting of coke and slag together with the reaction between them in a packed bed has not been systematically researched. The oxygen partial pressure at the 
lower end of the cohesive zone would be low, therefore, it would also be necessary to consider the progress of the melting oxide in a Fe stable atmosphere, as well as the wettability with coke.

In the present study, a method to promote thinning of the cohesive layer was explored. In order to investigate the effect of reduction of iron ore on softening and melting phenomena, experiments of softening and melting in an atmosphere of $\mathrm{CO} / \mathrm{CO}_{2}$ in which $\mathrm{FeO}$ or $\mathrm{Fe}$ become stable were employed, and the oxide on the coke bed was observed. The effect of atmosphere and composition on the softening and melting temperatures of a $\mathrm{CaO}-\mathrm{FeO}-\mathrm{SiO}_{2}-$ $\mathrm{Al}_{2} \mathrm{O}_{3}-\mathrm{MgO}$-based oxide and the change in wetting on a coke and graphite substrate were also investigated.

\section{Experimental Procedure}

The effect on softening, melting and dripping temperatures caused by the reduction of a $\mathrm{CaO}-\mathrm{FeO}-\mathrm{SiO}_{2}-\mathrm{Al}_{2} \mathrm{O}_{3}-$ $\mathrm{MgO}$-based oxide by $\mathrm{CO}$, in an atmosphere simulating that of a blast furnace, was studied. The coke bed was formed in a crucible in the same way as previously reported. ${ }^{21)}$ The metallurgical coke was prepared by crushing and screening to a small particle size $(1-2 \mathrm{~mm})$. An oxide tablet of $\mathrm{SiO}_{2}-\mathrm{CaO}-\mathrm{FeO}-\mathrm{Al}_{2} \mathrm{O}_{3}-\mathrm{MgO}$ was placed on the coke bed and heated to allow the softening, melting, and penetration behaviors to be observed. In order to investigate the contact between the carbonaceous material and the molten ore dripping into the coke bed, the oxide tablet was heated on a single plate of the coke or graphite substrate so that the wettability could be observed.

\subsection{Sample Preparation}

Reagent grade $\mathrm{Fe}_{2} \mathrm{O}_{3}, \mathrm{Fe}, \mathrm{CaCO}_{3}, \mathrm{SiO}_{2}, \mathrm{Al}_{2} \mathrm{O}_{3}$, and $\mathrm{MgO}$ were used in preparing the oxide sample. In order to form $\mathrm{FeO}, \mathrm{Fe}$ and $\mathrm{Fe}_{2} \mathrm{O}_{3}$ were mixed so as to become $\mathrm{FeO}$ in a stoichiometric ratio, completely melted in an iron crucible at $1723 \mathrm{~K}$, and then poured out onto a water-cooled copper plate.

The $\mathrm{FeO}$ was then pulverized in a mortar to a particle size (under $74 \mu \mathrm{m}$ ), while the $\mathrm{CaCO}_{3}$ was decomposed by keeping it at $1673 \mathrm{~K}$ for 14 hours to obtain $\mathrm{CaO}$.

A predetermined composition of reagents was weighed and homogeneously mixed in an agate mortar to prepare a sample. Then, $2 \mathrm{~g}$ of oxide mixture was pressed in a die to produce a tablet with a diameter of $10 \mathrm{~mm}$. The sample compositions are shown in Table 1. The $\mathrm{CaO} / \mathrm{SiO}_{2}$ ratio $(\mathrm{C} / \mathrm{S})$ was changed with an $\mathrm{FeO}$ concentration of 30 mass\%. Sample S1 is the standard sample, ${ }^{21)} \mathrm{S} 2$ and S3 (which are acidic and basic, respectively) were prepared in order to investigate the influence of $\mathrm{C} / \mathrm{S}$ on softening and melting phenomena. Approximately $2 \mathrm{~g}$ of the mixed

Table 1. Composition of sample.

\begin{tabular}{cccccc}
\hline Sample & $\mathrm{CaO}$ & $\mathrm{SiO}_{2}$ & $\mathrm{Al}_{2} \mathrm{O}_{3}$ & $\mathrm{MgO}$ & $\mathrm{FeO}$ \\
\hline $\mathrm{S} 1$ & 30.0 & 25.0 & 10.0 & 5.0 & 30.0 \\
$\mathrm{~S} 2$ & 16.5 & 38.5 & 10.0 & 5.0 & 30.0 \\
$\mathrm{~S} 3$ & 38.5 & 16.5 & 10.0 & 5.0 & 30.0 \\
\hline
\end{tabular}

sample was weighed and compacted to form a tablet of $\varphi$ $10 \mathrm{~mm}$.

\subsection{Observation of Softening and Melting Behavior}

Coke particles of $1-2 \mathrm{~mm}$ diameter were poured into a shallow aluminum crucible ( $\varphi 23 \mathrm{~mm}$ in diameter) and the oxide tablet was placed on the coke bed. The concentrations of fixed carbon, volatile matter, ash and water in the coke were $87.66,0.26,12.08$ and 0.28 mass $\%$, respectively. A horizontal electric resistance furnace with a mullite tube ( $935 \mathrm{~mm}$ ID) was employed for the observation of the tablet. The sample was placed in the center of the tube, and the changes in the appearance of the sample were observed using a camera placed close to the end of the reaction tube. Details of the experimental apparatus are noted elsewhere. ${ }^{21)}$ The temperature of the furnace was controlled by a proportional-integral-derivative (PID) controller connected to a thermocouple located near the sample. The temperature difference between the sample and the hot zone is within $3 \mathrm{~K}$. In addition there might be some endothermic temperature change due to the melting and chemical reaction. $\mathrm{N}_{2}$ gas was introduced at a flow rate of $100 \mathrm{ml} / \mathrm{min}$ $(0.10 \mathrm{~m} / \mathrm{min})$ and the temperature was increased to $1173 \mathrm{~K}$ at a heating rate of $10 \mathrm{~K} / \mathrm{min}$. Then enough volume of $\mathrm{CO} /$ $\mathrm{CO}_{2}$ gas to reduce the $\mathrm{FeO}$ in the sample was introduced at a flow rate of $100 \mathrm{ml} / \mathrm{min}(0.10 \mathrm{~m} / \mathrm{min})$, and the mixing ratio of $\mathrm{CO} / \mathrm{CO}_{2}$ was controlled at $4 / 6,5 / 5,6 / 4,8 / 2$ and $9 / 1$ with the use of mass flow controllers. The temperature was subsequently increased to $1723 \mathrm{~K}$ in an atmosphere of $4 / 6-6 / 4$ or $1773 \mathrm{~K}$ in an atmosphere of $8 / 2$ and $9 / 1$ at a rate of $5 \mathrm{~K} / \mathrm{min}$, and then maintained at these temperatures for $1800 \mathrm{~s}$. As shown in a typical stability diagram of the Fe$\mathrm{O}-\mathrm{C}$ system, ${ }^{31)} \mathrm{FeO}$ and $\mathrm{Fe}$ are stable phases in an atmosphere of 4/6-6/4 and 8/2-9/1, respectively. Under these conditions, reduction and oxidation of the sample by the atmosphere and reduction by coke occur simultaneously. In addition, coke is oxidized by the gas phase, and coke ash and slag react with each other. These reactions, as well as the ash, might affect wetting. The actual reaction of the iron ore in the blast furnace depends on the size of the ore, the temperature and the atmosphere in the blast furnace. The softening, melting, and permeation temperatures of the oxide were measured by observing the changes in the shape of the tablet.

In the present experiment, softening, melting and penetration behaviors were determined from the temperature of atmosphere near the sample and the changes in the shape of the sample. ${ }^{21)}$ As the tablet partially formed a liquid phase with heating, the shape of the surface changed. The temperature at which the shape of the surface began to change was taken as the softening temperature. When the softened sample was further heated, the surface became a smooth droplet shape - an irregular shape was not observed - and the temperature at which the entire surface became smooth was taken as droplet formation, namely the melting temperature. The droplet stayed on the surface of the coke bed for a while after its formation, i.e., it did not permeate into the bed right after sample melting. Once permeation occurred, it was completed in a short time. This temperature was taken as the permeation temperature. 


\subsection{Observation of Interfaces between Coke-oxide and Graphite-oxide during the Reducing Reaction}

If the liquidus temperature of the sample is high, and the oxide is wettable with coke, the liquid part of the sample partially permeates into the coke bed during droplet formation and only the solid phase remains on the coke bed. Therefore it was difficult to confirm the change in wettability. Here, instead of coke particles, plates of coke and graphite, which were cut to $\varphi 20 \mathrm{~mm} \times \mathrm{t} 4 \mathrm{~mm}$ and whose surface was polished, were placed horizontally in the crucible. An oxide tablet of sample S1 was placed on the plates to observe the change of wetting and then the cross section of the interface was observed by a Field Emission Electron Probe Micro Analyzer (EPMA). Firstly, the sample was heated to $1173 \mathrm{~K}$ in $\mathrm{N}_{2}$ and then heated to $1723 \mathrm{~K}$ or $1773 \mathrm{~K}$ at $5 \mathrm{~K} / \mathrm{min}$ in an atmosphere of CO/ $\mathrm{CO}_{2}$ (predetermined mixing ratio), then taken out of the furnace and quenched under an $\mathrm{Ar}$ stream. The change in appearance of the sample during heating was recorded by the camera. The sample after quenching was first packed in resin and then cut, the cross section was polished and used as an analyzing sample for Scanning Electron Microscope (SEM) and EPMA.

\section{Experimental Results}

\subsection{Impact of Atmosphere on the Softening Tempera- ture of Oxides}

Figure 1 shows the shape of sample 1 heated in a $\mathrm{CO} /$ $\mathrm{CO}_{2}$ mixture of 5/5. Panel a) shows the shape between the softening and melting temperature; b) shows the shape at the melting temperature; c) shows the shape at $1723 \mathrm{~K}$; and d) is the shape at $1723 \mathrm{~K}$ after holding for $20 \mathrm{~min}$. While holding the sample at $1723 \mathrm{~K}$, the melt penetrated into the coke bed.

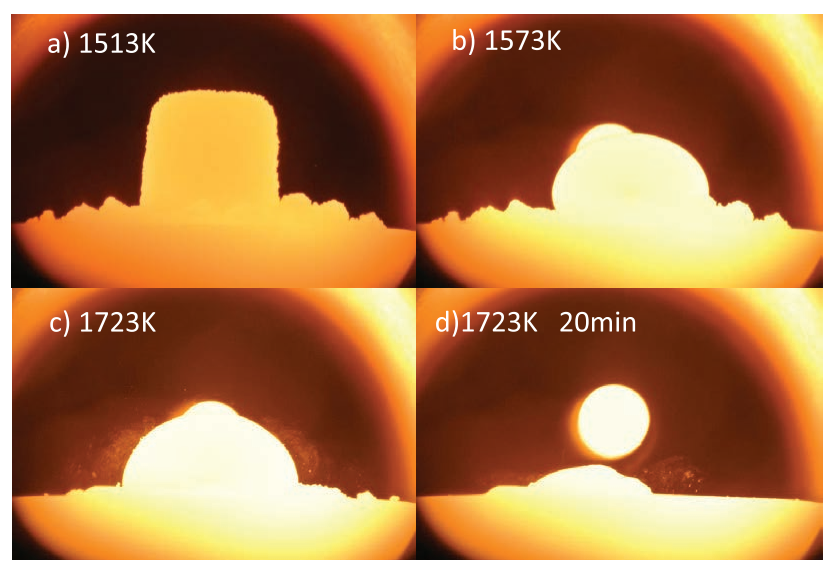

Fig. 1. Shape change of $\mathrm{S} 1 \mathrm{CO} / \mathrm{CO}_{2}$ ratio of 5/5. (Online version in color.)
Figure 2 shows the influence of the $\mathrm{CO} / \mathrm{CO}_{2}$ ratio in the atmosphere on the softening temperature of samples S1-S3. Experimental results from previous work ${ }^{21)}$ for S1 in a $4 / 6-6 / 4 \mathrm{CO} / \mathrm{CO}_{2}$ mixture were used. The horizontal axis denotes the $\mathrm{CO} / \mathrm{CO}_{2}$ ratio in the atmosphere. The open squares, circles, and triangles indicate the softening temperatures of S1, S2, and S3, respectively and the solid squares, circles, and triangles represent the melting temperature. At a $\mathrm{CO} / \mathrm{CO}_{2}$ ratio of $8 / 2$ and $9 / 1$, the samples remained on the coke bed with solid-liquid coexistence until $1773 \mathrm{~K}$, neither droplet formation nor penetration were observed. Therefore no melting temperatures were shown in the figure. The softening temperature was almost constant when the $\mathrm{CO} / \mathrm{CO}_{2}$ ratio was $4 / 6-6 / 4$, and increased with increasing partial pressure of $\mathrm{CO}$ over $8 / 2$. In S2, no liquid droplets were formed at $6 / 4$ and $1711 \mathrm{~K}$, a part of the liquid phase penetrated into the coke bed, and a residue was left.

The appearance of $\mathrm{S} 1$ at $1723 \mathrm{~K}$ is shown in Fig. 3. Sections (a), (b) and (c) show samples under $\mathrm{CO} / \mathrm{CO}_{2}$ ratios of 5/5,8/2 and 9/1 respectively. In (a), the sample became droplets, but in the case of b) and c) only the shape of the tablets changed and did not penetrate the coke bed. When the temperature was increased to $1773 \mathrm{~K}$, (b) still did not show any significant change in shape, whereas (c) melted and separated into metal and oxide phases and remained on the coke even at high temperature. For the S2 and S3 specimens with different basicity, the specimens partially melted in $\mathrm{CO} / \mathrm{CO}_{2}$ mixtures of $8 / 2$ and $9 / 1$, and the solid oxide remained on the coke bed even at $1773 \mathrm{~K}$. The softening and melting behavior clearly changed due to the progress of the reduction of $\mathrm{FeO}$ by the $\mathrm{CO}$ in the atmosphere.

Figure 4 shows the cross section of sample S1 that remained on the coke after heating to $1773 \mathrm{~K}$ under the $\mathrm{CO} /$

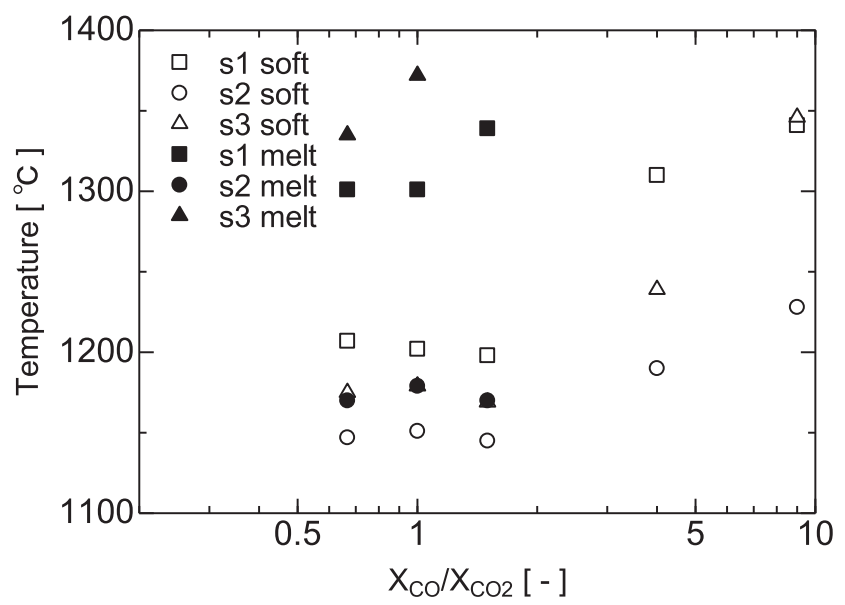

Fig. 2. Softening and melting temperatures in various $\mathrm{CO} / \mathrm{CO}_{2}$ atmosphere.

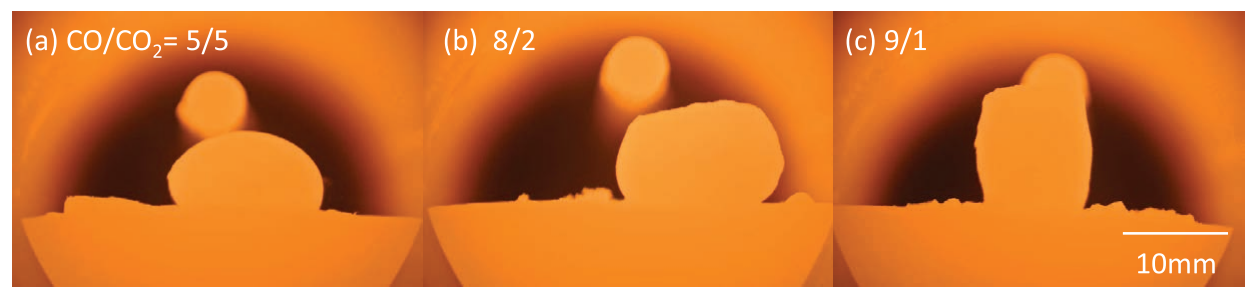

Fig. 3. Shape of $\mathrm{S} 1$ at $1723 \mathrm{~K}$ in various $\mathrm{CO} / \mathrm{CO}_{2}$ ratio. (Online version in color.) 
$\mathrm{CO}_{2}$ ratio of $8 / 2$ and $9 / 1$. In Fig. 4(a), the upper part of the cross section is oxide and the lower part is coke bed. It can be seen that the white color of the metallic iron disperses in the oxide phase and the microstructure of iron spreads throughout the oxide. A continuous structure of porous solid iron is formed, the solid and liquid oxide coexist in the structure and bubbles are entrapped in the slag phase. In the cross section of the sample in the $\mathrm{CO} / \mathrm{CO}_{2}$ ratio of $9 / 1$ shown in Fig. 4(b), the iron had melted, and the molten iron and slag phases clearly separated from each other. There are few residual bubbles.

Figure 5 shows the distribution of elements in position, outlined by the rectangle indicated in Fig. 4(a). The upper and lower sides show the iron and coke phases respectively. In the portion in contact with the coke in the lower part of the iron phase, the carbon concentration is above 2.5 mass $\%$ and it can be confirmed that the iron was melted, with carburization occurring according to the phase diagram of the $\mathrm{Fe}-\mathrm{C}$ system. ${ }^{32)}$ Also, as the distance from the interface with the coke increases, the carbon concentration decreases.

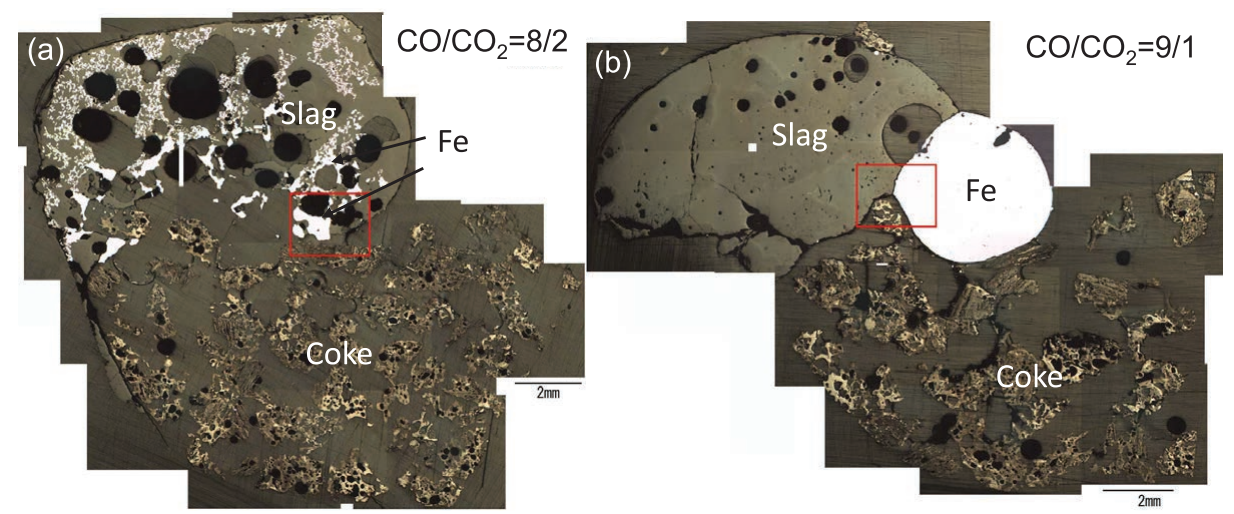

Fig. 4. Cross section of sample heated in $\mathrm{CO} / \mathrm{CO}_{2}$ atmosphere at composition of $8 / 2$ and $9 / 2$. (Online version in color.)

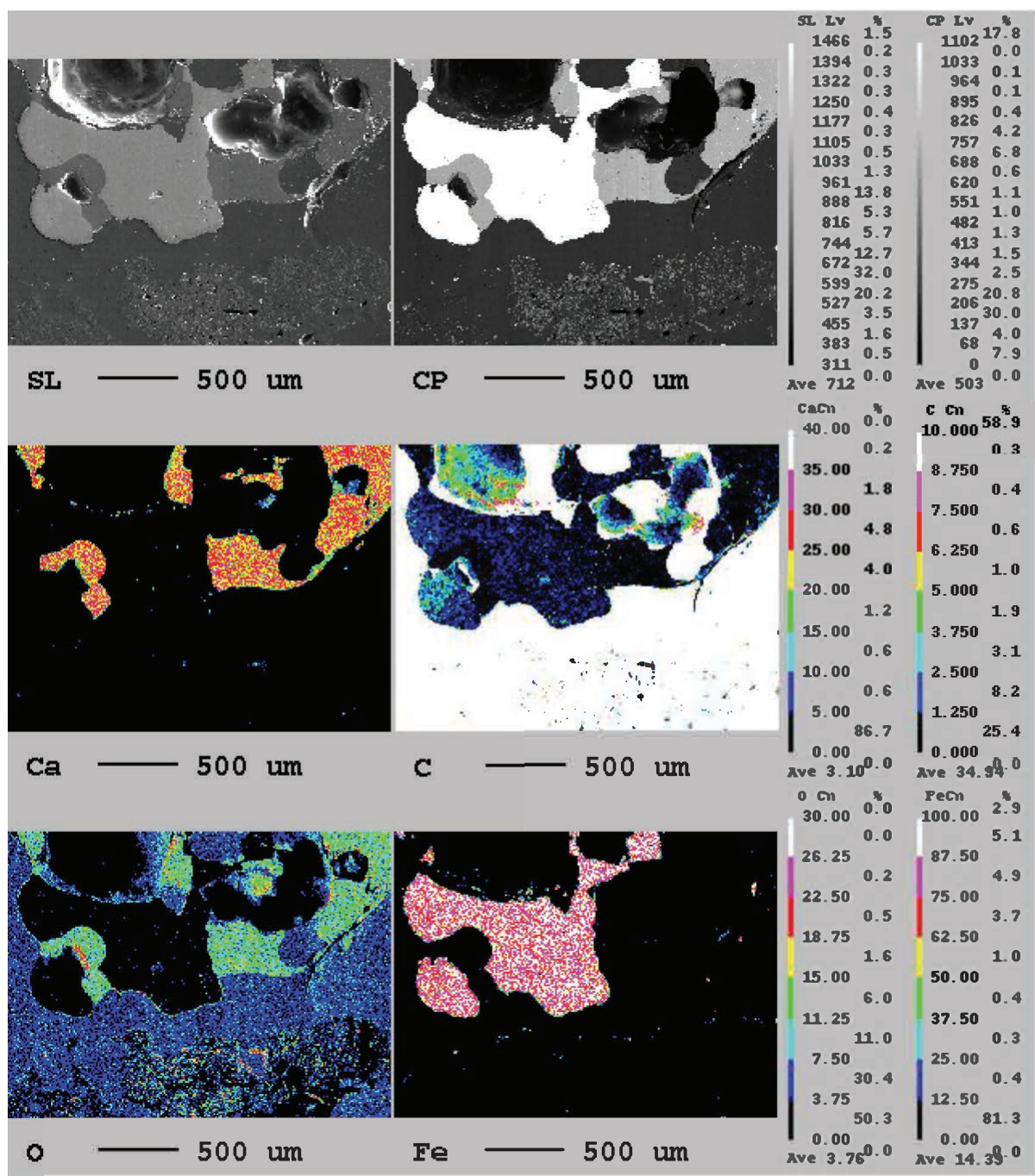

Fig. 5. Interface of coke bed and sample heated in $\mathrm{CO} / \mathrm{CO}_{2}=8 / 2$. (Online version in color.) 


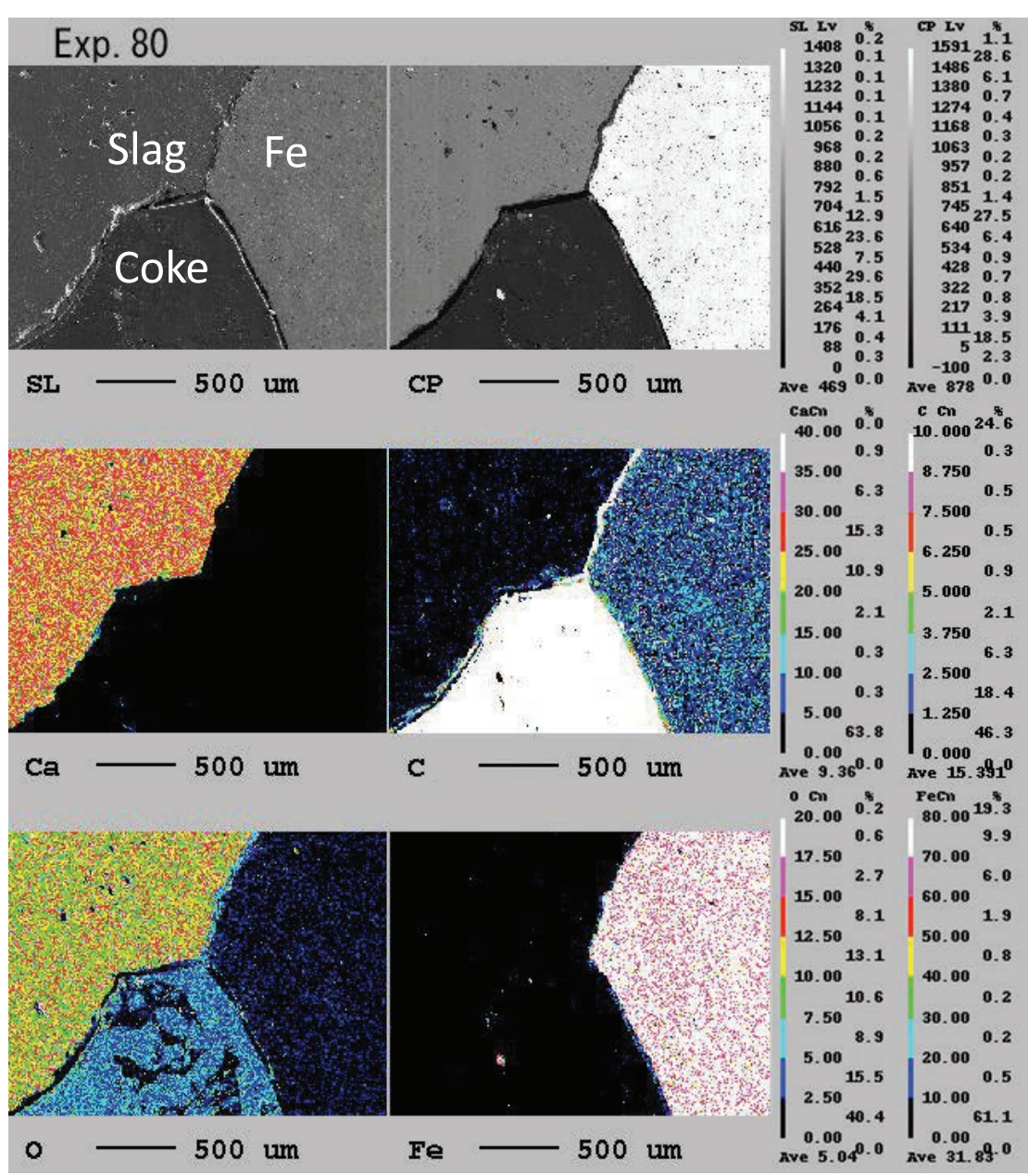

Fig. 6. Interface of coke bed and sample heated in $\mathrm{CO} / \mathrm{CO}_{2}=9 / 1$. (Online version in color.)

In addition, since the oxide and iron are mixed with each other and the interface in contact with the oxide phase is non-smooth, it can therefore be assumed that the iron is not completely melted.

Figure 6 shows the distribution of elements in the area outlined by the rectangle in Fig. 4(b), including molten iron, oxide and coke phases. The concentration of carbon in the iron near the interface is approximately 3 mass $\%$, and thus the iron in contact with the coke melted. However, by the end of the measurement the molten iron and the slag had melted completely and separated from each other, so that the iron did not penetrate into the coke bed.

In the reducing atmosphere, iron oxide was reduced to metallic iron, melted by carburization, and separated from the slag, but its penetration into the coke bed was not observed. When the carbon concentration in iron is low, the wettability is good, becoming poorer with increasing concentration of carbon. ${ }^{27)}$ In this experimental result, because the carbon concentration in the iron phase was as high as $3 \%$ carbon, the wettability was poor.

\subsection{Influence of Basicity on Softening Temperature in a Reducing Atmosphere}

Figure 7 shows a comparison between the softening temperatures of samples S1-S3 in various reducing conditions. The horizontal axis shows basicity (ratio of $\mathrm{CaO} /$ $\mathrm{SiO}_{2}$ ), while solid circles, open circles, triangles and squares respectively represent $\mathrm{CO} / \mathrm{CO}_{2}$ ratios of $4 / 6,6 / 4,8 / 2$ and

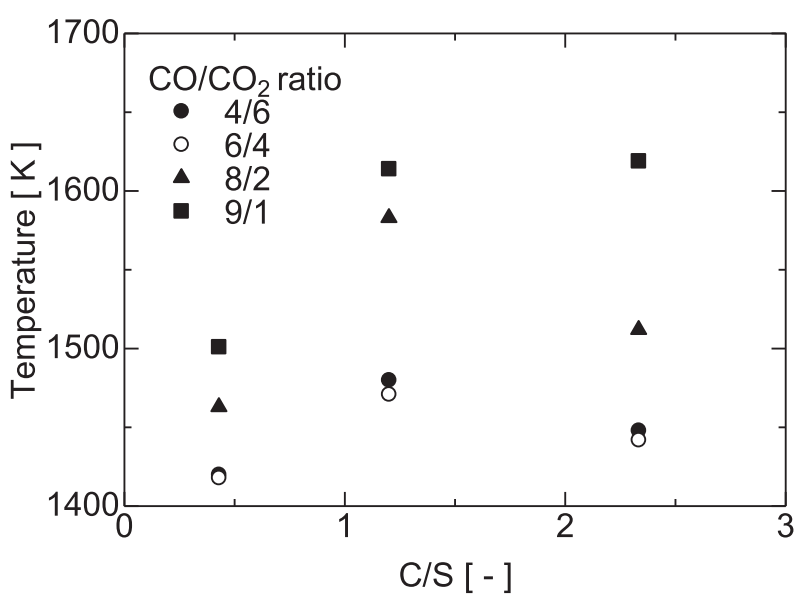

Fig. 7. Relationship between basicity and softening temperature in various atmosphere.

9/1. Regardless of basicity, it can be seen that there is no change in softening temperature at the $\mathrm{CO} / \mathrm{CO}_{2}$ ratios of 4/6-6/4. For the $8 / 2$ and $9 / 1$ ratios, the softening temperature increases with an increase in the $\mathrm{CO} / \mathrm{CO}_{2}$ ratio. When the $\mathrm{CO}$ ratio increases from $6 / 4$ to $9 / 1$ at low basicity (S2), the softening temperature increases by approximately 100 $\mathrm{K}$ under the experimental conditions. On the other hand, for S3 with high basicity, a softening temperature increasing to approximately $200 \mathrm{~K}$ is seen. The influence of the atmosphere on the softening temperature is stronger as the 
basicity becomes higher.

\subsection{Influence of Atmosphere on Wetting}

In order to investigate the change in wettability affecting the penetration of liquid droplets into the packed bed, S1 was heated on a single plate of both coke and graphite substrates to $1723 \mathrm{~K}$ in an atmosphere with a $\mathrm{CO} / \mathrm{CO}_{2}$ ratio of $5 / 5$, so that its shape could be observed. Figures 8 and 9 show the shapes of the sample at $1593 \mathrm{~K}, 1643 \mathrm{~K}$ and $1723 \mathrm{~K}$ on coke and graphite substrates, respectively. Since the temperature is increased at a rate of $5 \mathrm{~K} / \mathrm{min}$, the time from $1593 \mathrm{~K}$ to $1643 \mathrm{~K}$ and that from $1643 \mathrm{~K}$ to $1723 \mathrm{~K}$ are 10 minutes and 16 minutes, respectively. Both samples form liquid droplets at approximately $1573 \mathrm{~K}$. The contact angle at that time was observed to be approximately equal at $127^{\circ}$ and $130^{\circ}$ on the coke and the graphite substrates, respectively. The apparent size of the droplet fluctuated with the generation of gas. At $1593 \mathrm{~K}$, the wetting angle is almost the same for both substrates. At $1643 \mathrm{~K}$, the wetting angle of the droplet on the graphite is about $90^{\circ}$ and it changed from a non-wetting to a wetting state. At $1723 \mathrm{~K}$, the wetting angle further decreases. On the other hand, the sample on the coke kept a non-wetting state, even if it was heated up to $1723 \mathrm{~K}$.

These samples were heated to $1723 \mathrm{~K}$ and quenched to prepare specimens for observation in cross section. A cross-sectional view, together with an enlarged interface of the carbonaceous material with the droplet, are shown in
Figs. 10-12. For the sample on coke (Fig. 10(a)), an iron phase is formed along the lower surface of the initial droplet that appears white in the vicinity of the droplet and shows its shape. On the right side of the droplet, oxides exist outside the thin iron phase and molten oxides flow out of the solid iron shell produced during the temperature increase. On the other hand, the sample on graphite is clearly separated into iron (white) and slag (gray). It had been reported that the change in wettability due to the progress of reduc-

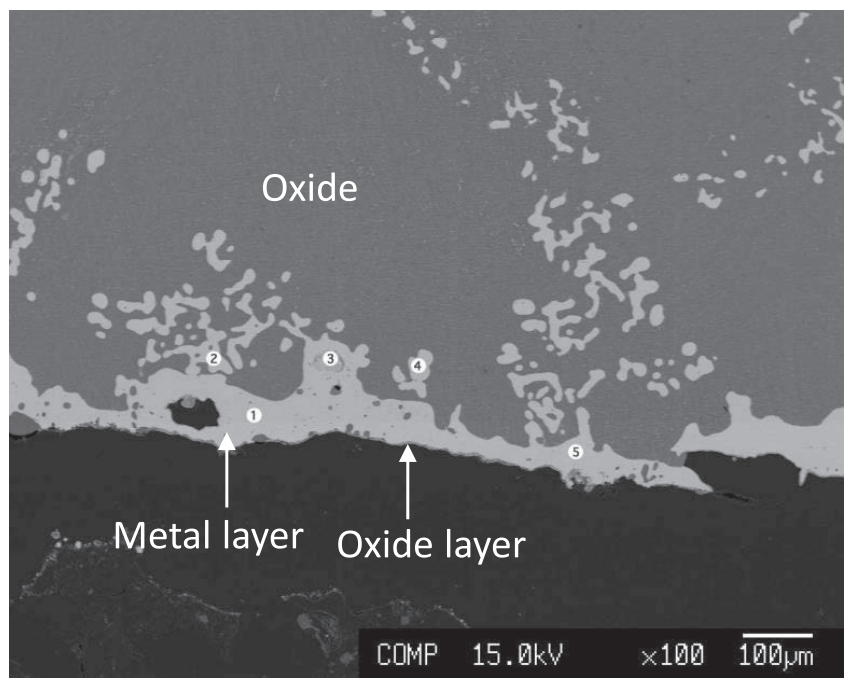

Fig. 11. Interface of sample and coke substrate.

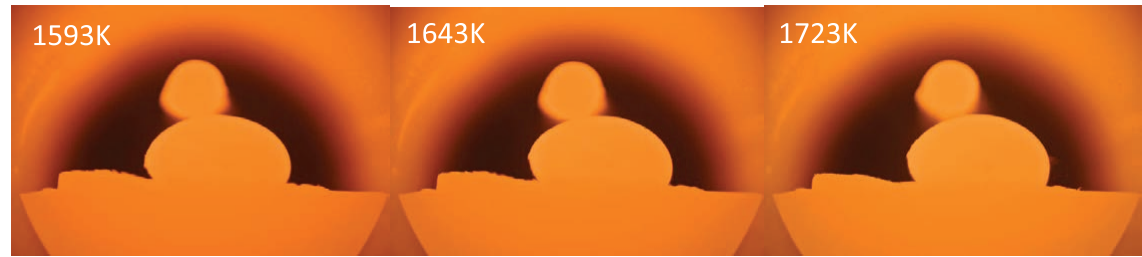

Fig. 8. Changes in oxide shape during heating on coke substrate. (Online version in color.)

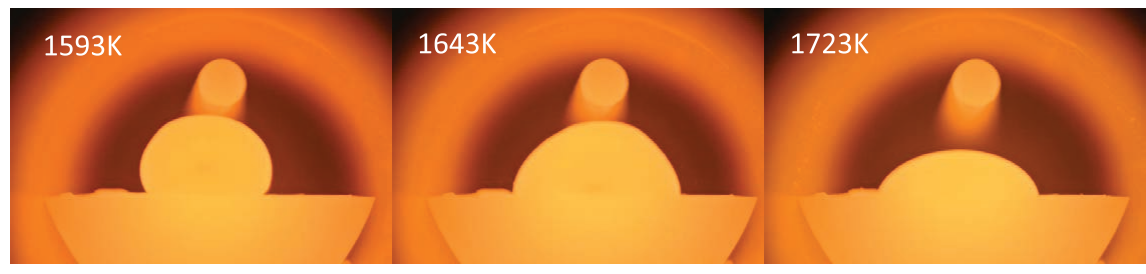

Fig. 9. Changes in oxide shape during heating on graphite substrate. (Online version in color.)

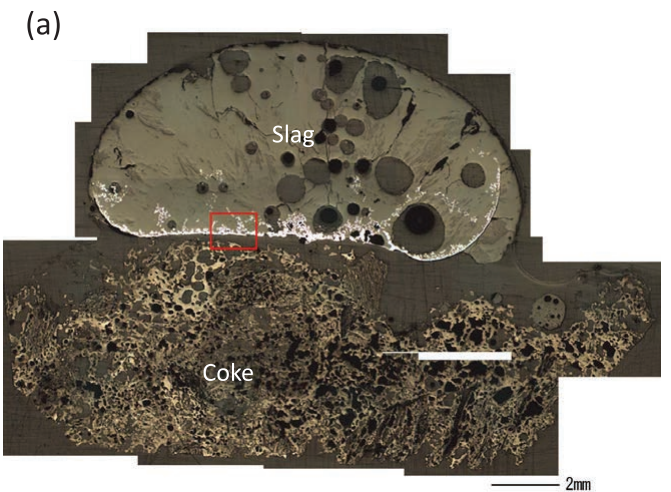

(b)

Fig. 10. Cross section of sample heated on coke and graphite substrate. (Online version in color.) 
tion is also affected by the time after contact and the slag composition. ${ }^{18-20)}$ In this experiment, the apparent wettability of the slag on the coke and graphite surfaces depended on the presence or absence of a solid iron film formed at the interface. As shown in Fig. 10(a), the formation of solid iron prevented contact between the slag and the carbonaceous material, that showed a different wetting mechanism. In addition, it can be seen from Fig. 11(b) that when the slag and the graphite are in contact with each other, they become wet in a short time.

Figures 11 and 12 respectively show enlarged views of the area indicated by the frame in Figs. 10(a) and 10(b). Composition of the iron phase at the positions shown in Figs. 11 and 12 were analyzed. The results are shown in Table 2. The total deviates from $100 \%$ due to measurement errors. The concentration of carbon in the samples on the coke substrate was in the range of $0.5-1.7 \%$, that on the graphite was $1.2-4.4 \%$. Considering the phase diagram in the $\mathrm{Fe}-\mathrm{C}$ system, the iron on graphite would be carburized enough and melted at $1723 \mathrm{~K}$. On the other hand, for the sample on coke, since carbon concentration in iron is within the range of solid iron or solid-liquid coexistence, the oxide and coke are divided by the solid iron phase. Furthermore, a very thin oxide layer exists between the iron and the coke

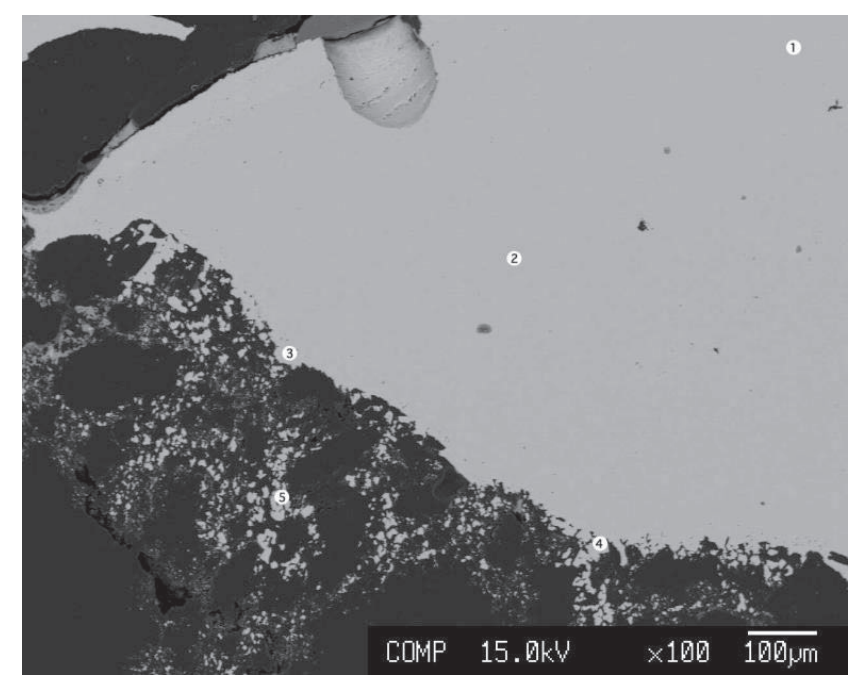

Fig. 12. Interface of sample and graphite substrate.

Table 2. Composition of droplet vicinity of coke and graphite.

\begin{tabular}{ccccccccc}
\hline Substrate Position & $\mathrm{C}$ & $\mathrm{Ca}$ & $\mathrm{Mg}$ & $\mathrm{Si}$ & $\mathrm{O}$ & $\mathrm{Fe}$ & $\mathrm{Al}$ \\
\hline & 1 & 0.656 & - & 0.002 & - & 0.038 & 102.3 & - \\
& 2 & 0.587 & 0.026 & - & 0.025 & 0.127 & 101.8 & - \\
Coke & 3 & 1.66 & 0.133 & 0.091 & 0.968 & 4.30 & 98.7 & 0.168 \\
& 4 & 0.58 & 0.116 & - & 0.079 & 0.094 & 97.2 & 0.014 \\
& 5 & 0.567 & - & - & 0.017 & 0.08 & 103.2 & - \\
\hline \multirow{3}{*}{ Graphite } & 1 & 4.28 & - & - & - & 0.007 & 96.1 & - \\
& 2 & 4.43 & - & - & 0.094 & - & 95.5 & 0.015 \\
& 4 & 1.40 & - & 0.014 & 0.013 & 0.064 & 99.8 & 0.043 \\
& 5 & 57.9 & 0.022 & - & 0.036 & 1.179 & 3.52 & - \\
\hline
\end{tabular}

phases. This oxide, which might be derived from ash contained in the coke, separates the iron phase from the carbon in the coke. There is a possibility that the oxide film present at the interface with the coke prevents carburization of the iron phase. On the other hand, as shown in Fig. 12, the iron phase is in direct contact with the graphite and iron permeates the grain boundary of the graphite substrate.

In previous research on iron ore reduction, it has been shown that there is no correlation between the melting temperature and dripping temperature. ${ }^{21)}$ In order to enhance the dripping from the lower part of the cohesive zone to the coke bed, it would be effective to improve the wettability. If the reactivity at the interface between the carbonaceous material and the oxide is improved, the wettability would be improved and the melting of the iron phase would be enhanced, and therefore the dripping temperature could be decreased. For that purpose, it would be effective to promote the reaction between carbon and iron by reducing the ash in coke.

\section{Discussion}

\subsection{Influence of FeO Reduction on Softening Tempera- ture}

When the oxide containing Fe was heated in an atmosphere simulating a blast furnace, it was confirmed that the softening temperature increases with increase in the $\mathrm{CO}$ partial pressure, as shown in Fig. 2. Reduction of $\mathrm{FeO}$ by a gas phase is expressed as follows:

$$
\begin{array}{r}
\mathrm{FeO}(\mathrm{s})+\mathrm{CO}(\mathrm{g})=\mathrm{Fe}(\mathrm{s})+\mathrm{CO}_{2}(\mathrm{~g}) \ldots \ldots \ldots \ldots . . . . . \\
\Delta G^{\circ}=-17200+21.3 T[\mathrm{~J} / \mathrm{mol}](1185-1644 \mathrm{~K})^{28)} . .
\end{array}
$$

The ratio of $\mathrm{CO} / \mathrm{CO}_{2}$ at the $\mathrm{Fe} / \mathrm{FeO}$ equilibrium can be derived from the standard free energy change. In the temperature range of $1173-1723 \mathrm{~K}, \mathrm{Fe} / \mathrm{FeO}$ would coexist in the $\mathrm{CO} / \mathrm{CO}_{2}$ ratio of $6 / 4-8 / 2$. Therefore, when the $\mathrm{CO} /$ $\mathrm{CO}_{2}$ ratio is below $6 / 4$ or over $8 / 2$, the $\mathrm{FeO}$ and $\mathrm{Fe}$ are stabilized. From Fig. 2, the softening temperature of $\mathrm{S} 1$ is approximately $1473 \mathrm{~K}$ in the $\mathrm{FeO}$ stable condition, however the temperature is increased to $1573 \mathrm{~K}$ in the Fe stable condition. The cross section of the sample heated in a $\mathrm{CO} /$ $\mathrm{CO}_{2}$ ratio of $8 / 2$ in Fig. 4 shows that Fe was dispersed in the oxide in the vicinity of the contact surface with the coke. In addition, at a $\mathrm{CO} / \mathrm{CO}_{2}$ ratio of $9 / 1$, further reduction and carburization progressed, since the liquidus temperature decreases with increasing concentration of $\mathrm{C}$ in $\mathrm{Fe}$, and the metallic iron melted and aggregated.

It can be seen that the rate of reduction of the iron oxide in the tablet sample depends on the $\mathrm{CO} / \mathrm{CO}_{2}$ ratio in the surrounding atmosphere. As discussed in the next section, when the $\mathrm{FeO}$ concentration decreases due to reduction by a gas phase, both the solid and liquidus temperatures of the oxide will be increased. Also, when metallic iron is formed from $\mathrm{FeO}$, a structure of iron is formed and oxides are entrapped therein, so that the shape of the tablet is kept even if the oxide has partially melted. The iron melts with the progress of reduction and carburization. As described above, in the reducing atmosphere, the formation of metallic iron and the compositional change of the slag increased the 
softening and dripping temperatures. When the reduction progresses rapidly, since the $\mathrm{Fe}-\mathrm{C}$ melt is formed at an early stage, the temperature difference between the softening and dripping can be reduced.

\subsection{Influence of Reduction Ratio and Concentration of FeO on Softening and Melting of the Oxide Phase}

The temperature dependence of the liquid fraction in the oxide phase when sample $\mathrm{S} 1$ was reduced and the $\mathrm{FeO}$ concentration in the oxide decreased was calculated using a thermodynamic database (FactSage 7.0) ${ }^{34)}$ (Fig. 13). Here, the $\mathrm{Fe}$ formed from reduction is not taken into consideration. The relationship between temperature and liquid phase rate is shown in Fig 13. In the estimation, the reduction of a $\mathrm{CaO}-\mathrm{SiO}_{2}-\mathrm{Al}_{2} \mathrm{O}_{3}-\mathrm{MgO}$ system with 30 mass $\%$ of $\mathrm{FeO}$ was considered. Only the concentration of $\mathrm{FeO}$ was decreased while the proportion of $\mathrm{CaO}-\mathrm{SiO}_{2}-\mathrm{Al}_{2} \mathrm{O}_{3}-\mathrm{MgO}$ was kept constant. In the diagram, from the top, the lines represent no reduction, 2/3 reduced, and 5/6 reduced. During the composition of S1, a liquid phase of Olivine is formed at 1497 $\mathrm{K}$. As the reduction progresses, it can be seen that the generation temperature of the initial melt increases. When the $\mathrm{FeO}$ is completely reduced to $\mathrm{Fe}$, the initial melt becomes a $\mathrm{CaO}-\mathrm{Al}_{2} \mathrm{O}_{3}-\mathrm{SiO}_{2}$-based liquid phase, and the solidus temperature increases remarkably to $1570 \mathrm{~K}$. According to the experimental results in Fig. 2, the softening temperature of the sample in a $\mathrm{CO} / \mathrm{CO}_{2}$ ratio of $8 / 2$ and $9 / 1$ increases with the increase of the $\mathrm{CO}$ concentration. Figure 13 shows that the $\mathrm{FeO}$ in the oxide is easily reduced because the $\mathrm{CO}$ concentration is higher, while the $\mathrm{FeO}$ concentration in the oxide at melting temperature is lowered. These temperatures are slightly higher than those from the $100 \%$ reduction ratio, however it can be confirmed that the increase in the solidus temperature is reflected by the reduction of $\mathrm{FeO}$. When $2 / 3$ of the $\mathrm{FeO}$ was reduced, the solidus temperature increased by $20 \mathrm{~K}$, moreover when reduction proceeded from $2 / 3$ to completion, the solidus temperature increased by $50 \mathrm{~K}$. In the experimental result where the initial $\mathrm{FeO}$ concentration in the oxide changed from $30 \%$ to $10 \%$, the influence of this variation on the softening temperature was small.22) Thus the presence or absence of a small amount of $\mathrm{FeO}$ strongly influences the softening temperature.

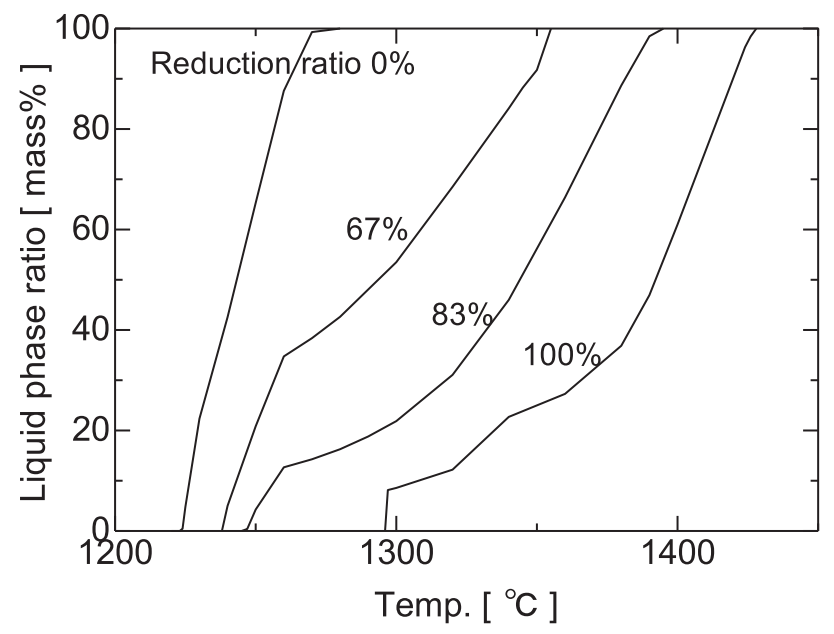

Fig. 13. Relationship between reduction rate of $\mathrm{FeO}$ and liquid ratio of oxide sample.
The softening temperature caused by a change in the $\mathrm{CO} /$ $\mathrm{CO}_{2}$ ratio is shown in Fig. 2. In an atmosphere in which $\mathrm{FeO}$ is stable the change in softening temperature is small. However the temperature increases with suppression of the liquid phase formation of Olivine, due to the reduction of $\mathrm{Fe}$ in an atmosphere in which $\mathrm{Fe}$ is stable. In addition, the increasing ratio of the liquid phase is suppressed with the increase in the reduction ratio. As shown in Fig. 13, when FeO is completely reduced, the liquidus temperature is $1703 \mathrm{~K}$, which is $150 \mathrm{~K}$ higher than liquid oxides containing $30 \% \mathrm{FeO}$.

\subsection{Optimization of Basicity for Softening and Melting}

In the present study, it was shown that during the reduction of $\mathrm{FeO}$, the ore progressed in a reducing atmosphere which simulated the temperature and gas inside the blast furnace. Here, the complete reduction of $\mathrm{FeO}$, a condition suppressing the increasing liquid ratio, was explored with varying basicity. The composition of the oxides used in the simulation is shown in Table 3 and the calculation result is shown in Fig. 14. Solidus temperatures of basicities 0.4, 1.2 and 2.4 are $1436 \mathrm{~K}, 1570 \mathrm{~K}$ and $1591 \mathrm{~K}$, respectively. These temperatures were about $30-60 \mathrm{~K}$ lower than the softening temperatures of samples in $9 / 1$ of the $\mathrm{CO} / \mathrm{CO}_{2}$ ratio shown in Fig. 7, but the tendency was consistent.

In the experimental results shown in Fig. 2, reduction seems to easily proceed where the atmosphere of $\mathrm{CO} / \mathrm{CO}_{2}$ is $9 / 1$, and the $\mathrm{FeO}$ concentration in the oxide at the start of softening has already been decreased. In the simulation using the thermodynamic database (see Section 4.2 above), the softening temperature is lower by $30-60 \mathrm{~K}$ than that

Table 3. Composition of oxide.

\begin{tabular}{cccccc}
\hline $\mathrm{C} / \mathrm{S}$ & $\mathrm{CaO}$ & $\mathrm{SiO}_{2}$ & $\mathrm{Al}_{2} \mathrm{O}_{3}$ & $\mathrm{MgO}$ & $\mathrm{FeO}$ \\
\hline 0.4 & 22.5 & 56.1 & 14.3 & 7.1 & 0 \\
0.8 & 34.9 & 43.7 & 14.3 & 7.1 & 0 \\
1.2 & 42.9 & 35.7 & 14.3 & 7.1 & 0 \\
1.6 & 48.4 & 30.2 & 14.3 & 7.1 & 0 \\
1.8 & 50.5 & 28.1 & 14.3 & 7.1 & 0 \\
2.0 & 52.4 & 26.2 & 14.3 & 7.1 & 0 \\
2.4 & 55.5 & 23.1 & 14.3 & 7.1 & 0 \\
\hline
\end{tabular}

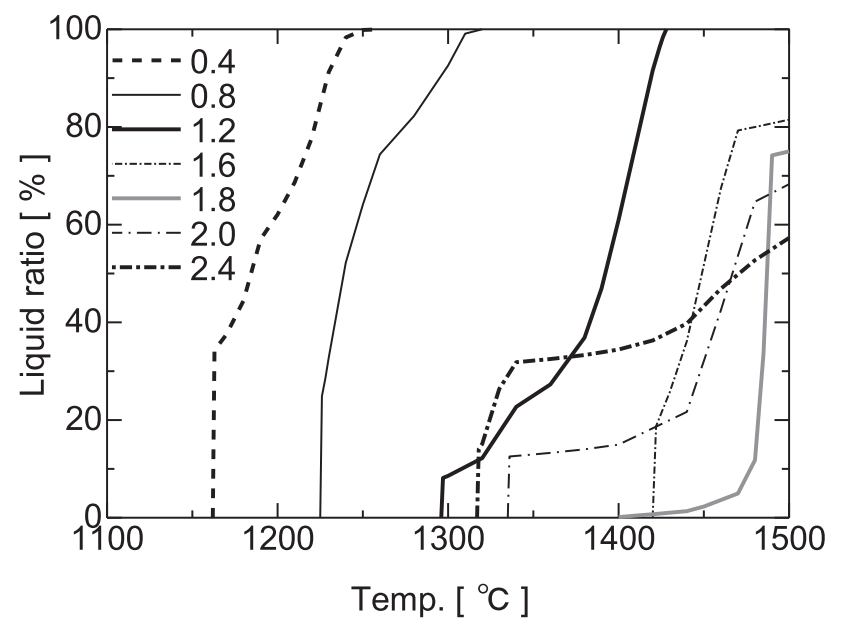

Fig. 14. Influence of basicity on liquid ratio of oxide sample. 
of the experimental result. The liquidus temperature is calculated to be lower than the softening temperature of the ore in the furnace, but the tendency is consistent. In an atmosphere in which $\mathrm{Fe}$ is stable, since the ore becomes a $\mathrm{CaO}-\mathrm{Al}_{2} \mathrm{O}_{3}-\mathrm{SiO}_{2}-\mathrm{MgO}$ system containing a low concentration of $\mathrm{FeO}$, the initial liquid phase would be a liquid of the $\mathrm{CaO}-\mathrm{Al}_{2} \mathrm{O}_{3}-\mathrm{SiO}_{2}$ system for a low basicity oxide, or a liquid of the $\mathrm{CaO}-\mathrm{Al}_{2} \mathrm{O}_{3}$ system for a high basicity oxide. When the basicity is 1.2 or less, since the equilibrated solid phase is Melilite, it completely melts below $1723 \mathrm{~K}$, and the temperature difference from the formation of liquid to entire melting is small. On the other hand, when the basicity is 1.8 , since the equilibrium phase is composed of dicalcium-silicate and goethite, the liquidus temperature is increased and the rate of the liquid phase formation is suppressed. Also, at the high temperature, it is saturated with dicalcium-silicate and does not melt completely even when it reaches the melting point of iron. When the basicity is over 2 , the initial liquid phase becomes a $\mathrm{CaO}-\mathrm{Al}_{2} \mathrm{O}_{3}$ system, and the liquidus temperature decreases as compared with the results using a basicity of 1.8. The equilibrium phase at high temperature is $\mathrm{CaO}$.

In order to reduce the temperature difference from softening to melting, it is necessary to select a low basicity composition in which dicalcium-silicate does not become a saturated phase below 1.2 in basicity. In this case, since the reduced solid iron entraps the molten slag, it is necessary to simultaneously decrease the melting point of iron by carburization. On the other hand, if basicity of 1.6-1.8 is used, the softening temperature increases and the temperature difference from the start of softening to the melting of iron can be reduced. Since dicalcium-silicate and $\mathrm{CaO}$ remain as undissolved oxides at the cohesive zone, it is necessary to study the influence of solid oxides on these liquid permeabilities. Furthermore, when the basicity is increased, the liquid temperature decreases and $\mathrm{CaO}$ tends to remain, which is disadvantageous for improving the air permeability.

\section{Conclusions}

In the present research, in order to investigate a method to decrease the thickness of the cohesive zone, the softening and melting behavior of the oxide on a coke bed in a reducing atmosphere as well as the change of wetting of the oxide melt on coke and graphite were investigated and the following results were obtained.

- In the Fe stable atmosphere in this experiment, reduction of iron progressed earlier than the initial softening of the tablet, and a solid iron structure was formed in the tablet.

- Since the FeO concentration in the oxide decreased, the softening temperature of the oxide increased with increasing $\mathrm{CO} / \mathrm{CO}_{2}$ ratio.

- In the case where the oxide coexists with the solid iron structure, droplets are not formed even if the liquid ratio increases.

- Where the ratio of $\mathrm{CO} / \mathrm{CO}_{2}$ in the atmosphere is high enough, the dissolution of iron by carburizing proceeds easily.
- Ash in coke reduces the reactivity at the interface between ore and coke and delays the carburization of solid iron at this interface.

\section{Acknowledgment}

This article is based on results obtained from "Development of technologies for environmentally harmonized steelmaking process, "COURSE50" project commissioned by the New Energy and Industrial Technology Development Organization (NEDO). Authors thank for the project, and also thank Mr. A. Ito, Ms. M. Hayasaka for their advice on experiments and analysis.

\section{REFERENCES}

1) S. Kondo: 33rd and 34th Nishiyama Memorial Seminar, ISIJ, Tokyo, (1975), 125

2) S. Matsuhashi, H. Kurosawa, S. Natsui, T. Kon, S. Ueda, R. Inoue and T. Ariyama: ISIJ Int., 52 (2012), 1990.

3) S. J. Chew, G. X. Wang, A. Yu and P. Zulli: Ironmaking Steelmaking, 24 (1997), 392.

4) Y. Pan, X. She, G. Wang, H. Zuo, J. Wang and Q. Xue: ISIJ Int., 59 (2019), 1192.

5) Y. Kashihara, Y. Iwai, K. Fukada and H. Nogami: ISIJ Int., 59 (2019), 1198.

6) D. J. Gavel, A. Adema, J. V. D. Stel, J. Sietsma, R. Boom and Y. Yang: ISIJ Int., 59 (2019), 778.

7) S. Ishihara and J. Kano: ISIJ Int., 59 (2019), 820.

8) W. Zhao, M. Chu, H. Wang, Z. Liu, J. Tang and Z. Ying: ISIJ Int., 58 (2018), 1989.

9) S. Natsui, K. Ohno, S. Sukenaga, T. Kikuchi and R. O. Suzuki: ISIJ Int., 58 (2018), 282.

10) H. Kurosawa, S. Matsuhashi, S. Natsui, T. Kon, S. Ueda, R. Inoue and T. Ariyama: ISIJ Int., 52 (2012), 1010.

11) D. D. Geleta and J. Lee: Metall. Mater. Trans. B, 49 (2018), 3594.

12) S. Ueda, T. Miki, T. Murakami, H. Nogami and T. Sato: Tetsu-toHagané, 99 (2013), 1 (in Japanese).

13) T. Miki and Y. Fujita: Int. Conf. on Smart Carbon Saving and Recycling for Ironmaking, ISIJ, Tokyo, (2013), 15.

14) M. Hayashi, S. Sukenaga, K. Ohno, S. Ueda, K. Sunahara and N. Saito: Tetsu-to-Hagané, 100 (2014), 211 (in Japanese).

15) T. Kon, S. Sukenaga and S. Ueda: ISIJ Int., 57 (2017), 1166.

16) T. Fukutake and V. Rajakumar: Trans. Iron Steel Inst. Jpn., 22 (1982), 355.

17) H. Ohgusu, Y. Sassa, Y. Tomita, K. Tanaka and M. Hasegawa: Tetsuto-Hagané, 78 (1992), 1164 (in Japanese).

18) H. Kokubu, A. Sasaki, S. Taguchi and N. Tsuchiya: Tetsu-to-Hagané, 68 (1982), 2338 (in Japanese).

19) M. Hino, T. Nagasaka, A. Katsumata, K. Higuchi, K. Yamaguchi and N. Kon-no: Metall. Mater. Trans. B, 30 (1999), 671.

20) M. Shin, J. S. Oh and J. Lee: ISIJ Int., 55 (2015), 2056.

21) S. Ueda, T. Kon, T. Miki, S. J. Kim and H. Nogami: Metall. Mater. Trans. B, 47 (2016), 2371.

22) S. Ueda, T. Kon, T. Miki, S. J. Kim and H. Nogami: ISIJ Int., 55 (2015), 2098.

23) M. Hayashi, S. Sukenaga, K. Ohno, S. Ueda, K. Sunahara and N. Saito: Tetsu-to-Hagané, 100 (2014), 211 (in Japanese).

24) V. Sahajwella, A. S. Mehta and R. Khanna: Metall. Mater. Trans. B, 35 (2004), 75.

25) T. W. Kang, S. Gupta, N. Saha-Chaudhury and V. Sahajwalla: ISIJ Int., 45 (2005), 1526.

26) J. S. Oh and J. Lee: J. Mater. Sci., 51 (2016), 1813.

27) T. Fukutake and V. Rajakumar: Trans. Iron Steel Inst. Jpn., 22 (1982), 355

28) H. Ohgusu, Y. Sassa, Y. Tomita, K. Tanaka and M. Hasegawa: Tetsuto-Hagané, 78 (1992), 1164 (in Japanese).

29) D. Jang, M. Shin, J. S. Oh, H. S. Kim, S. H. Yi and J. Lee: ISIJ Int., 54 (2014), 1251

30) S. Natsui, A. Sawada, K. Terui, Y. Kashihara, T. Kikuchi and R. O. Suzuki: Chem. Eng. Sci., 175 (2018), 25.

31) A. Babich, D. Senk, H. W. Gudenau and K. Th. Mavrommatis: Ironmaking Textbook, Institut für Eisenhüttenkunde der RWTH Aachen, Aachen, (2008), 186.

32) J. F. Elliott, M. Gleiser and V. Ramakrishna: Thermochemistry for Steelmaking, Vol. II, Addison-Wesley, Reading, MA, (1963), 359.

33) K. Ogino: Bull. Jpn. Inst. Met., 11 (1972), 323 (in Japanese).

34) Factsage, Ecole Polytechnique, CRCT, Montreal, (2001). 